\title{
Production and properties of bacterial cellulose by the strain Komagataeibacter xylinus B-12068
}

\author{
Tatiana G. Volova $^{\text {a,b }}$ Svetlana V. Prudnikova ${ }^{a}$, Aleksey G. Sukovatyi ${ }^{a, b}$, Ekaterina I. Shishatskaya ${ }^{\text {a,b }}$ \\ ${ }^{a}$ Siberian Federal University, 79 Svobodny pr, 660041, Krasnoyarsk, Russian Federation \\ ${ }^{\mathrm{b}}$ Institute of Biophysics SB RAS, Akademgorodok 50, 660036, Krasnoyarsk, Russian Federation
}

Correspondence author: Tatiana G. Volova, Institute of Biophysics SB RAS, Siberian Federal University, Akademgorodok 50/50, Krasnoyarsk, Russian Federation.

E-mail: volova45@mail.ru

Tel.: +7 (391) 2494428

Fax: +7 (391) 2433400

Abstract

A strain of acetic acid bacteria, Komagataeibacter xylinus B-12068, was studied as a source for bacterial cellulose (BC) production. The effects of cultivation conditions (carbon sources, temperature, and $\mathrm{pH}$ ) on $\mathrm{BC}$ production and properties were studied in surface and submerged cultures. Glucose was found to be the best substrate for BC production among the sugars tested; ethanol concentration of $3 \%(\mathrm{w} / \mathrm{v})$ enhanced the productivity of $\mathrm{BC}$. The composition of the medium and the cultivation regimes, ensuring a high production of $\mathrm{BC}$ on glucose and glycerol, up to 2.4 and $3.3 \mathrm{~g} / \mathrm{L} \cdot$ day, respectively, have been developed. $\mathrm{C} / \mathrm{N}$ elemental analysis, emission spectrometry, SEM, DTA, and X-Ray were used to investigate the structure and physical and mechanical properties of the BC produced under different conditions. MTT assay and SEM showed that native cellulose membrane did not cause cytotoxicity upon direct contact with NIH 3 T3 mouse fibroblast cells and was highly biocompatible.

Keywords: Bacterial cellulose, growth conditions, Komagataeibacter xylinus

\section{Introduction}

Cellulose is extracellular polysaccharide synthesized by higher plants, lower phototrophs, and prokaryotes belonging to various taxa: Gluconacetobacter, Acetobacter, Komagataeibacter (Tanaka, Murakami, Shinke, \& Aoki, 2000; Yamada et al., 2012; Gullo et al., 2017; Tabaii and Emtiazi, 2017 et al). Except for bacteria and tunicates, cellulose is a component of the cell wall of plants, algae, and slime molds (Dictyostelium) (Saxena \& Brown, 2005). Cellulose is used in a variety of applications in food and paper industries, medicine, and pharmaceutics. The chemical structure of bacterial cellulose (BC) is similar to that of plant-derived cellulose, but is has unique physical, mechanical, and chemical properties such as high strength, elasticity, gas permeability, high water-holding capacity, porosity, etc. Gel pellicles of BC have an ordered structure: they are 3D networks consisting of ribbon-like randomly oriented cellulose microfibrils. This structural arrangement of $\mathrm{BC}$ and its high compatibility with biological tissue make it attractive material for reconstructive surgery; and cell and tissue engineering - as carrier for drugs (Ma, Wang, Guan, \& Wang, 2010; Saska et al., 2011; Wang et al., 2017; Belosinschi, Tafanica, 2018; He et al., 2018).

In the literature, many methods for the synthesis of $\mathrm{BC}$ have been described, on various C-substrates, including wastes, involving strains, which are differ significantly in their production characteristics. Acetic acid bacteria of the genus Komagataeibacter, which were formerly known as Gluconacetobacter xylinus (Yamada et al., 2012), are currently studied as effective BC producers. Different strains of acetic acid bacteria are able to synthesize bacterial cellulose (BC) from various carbon sources, including wastes, with different production (Park, Jung, \& Park, 2003; Mohammadkazemi, Azin, \& Ashori, 2015). The highest BC yields reported in the literature were 1.2-4.5 g/L (Castro et al., 2012; Ruka, Simon, \& Dean 2012) and $5.96 \mathrm{~g} / \mathrm{L}$ - from the culture of a mutant strain (Hungund, \& Gupta, 2010). The achieved outputs of the BC are differ in significant and range, which is the reason for the optimization of the biosynthetic technologies, oriented to increase the productivity of processes.

To increase the scale of production of bacterial cellulose and to widen the range of its applications, it is necessary to have bacterial strains capable of synthesizing high yields of this valuable product of biotechnology. Therefore, much of recent research has been focused on finding new cellulose-producing strains and improving the fermentation techniques.

The purpose of the present study was to investigate the strain Komagataeibacter xylinus B-12068 as a new producer of bacterial cellulose and evaluate the influence of culture conditions on the structure and properties of BC.

\section{Methods}

\subsection{Characterization of the bacterial strain}

A bacterial strain Komagataeibacter xylinus B-12068 was isolated from the fermented tea (kombucha) Medusomyces gisevii J. Lindauon Hestrin-Schramm (HS) medium (Hestrin \& Schramm, 1954). The strain was identified based on its morphological, biochemical, genetic, and growth parameters. The strain Komagataeibacter xylinus was deposited in the Russian National Collection of Industrial Microorganisms (VKPM) with registration number VKPM B-12068. The morphology of bacterial cells was studied in Gram-stained preparations. The 
phenotypic properties were studied using conventional microbiological techniques. The morphology of vegetative cells; spore formation; motility; reaction to Gram staining; requirement for growth factors; presence of nitrate reductase; catalase, oxidase, amylase, proteinase activities; antibiotic sensitivity and $\mathrm{NaCl}$ sensitivity were determined. Growth on carbon sources, such as glucose, sucrose, maltose, galactose and mannitol was tested in the basal HS-medium supplemented with $2 \%(\mathrm{w} / \mathrm{v})$ of each carbohydrate. The strain produced bacterial cellulose (BC) in surface and submerged cultures.

2.2. Cultivation of the strain and production of bacterial cellulose

The collection culture of K. xylinus B-12068 was maintained on the Hestrin-Schramm (HS) agar medium. The standard HS medium contained $(\%, \mathrm{w} / \mathrm{v})$ : glucose -2 , peptone -0.5 , yeast extract -0.5 , Na2HPO4 -0.27 , and citric acid - 0.115 (Hestrin \& Schramm, 1954).

The pre-culture was performed on the HS agar. Then, the colonies were transferred into the flask containing liquid HS medium and cultivated for 7 days at a temperature of $30^{\circ} \mathrm{C}$ under static conditions. To investigate the influence of the culture conditions on $\mathrm{BC}$ biosynthesis and to find the conditions maximizing cellulose yield, we modified the standard medium by replacing glucose by other carbon sources (maltose, mannitol, sucrose or galactose), varying initial $\mathrm{pH}$ values (3.2-4.8) by adding acetate or citrate, varying the temperature of the medium $\left(20-37^{\circ} \mathrm{C}\right)$, and adding various concentrations of ethanol $(0.5-3.0 \%)$ to the medium, based on the data indicating that ethanol oxidized to acetate was a growth substrate and energy source for K. xylinus (Yamada et al., 2012). BC production by the strain was investigated under different culture conditions. Static cultivation was performed in the surface mode in Petri dishes, 1500-ml glass trays, or 250- to 500-ml glass flasks, which contained different volumes of the medium. Submerged cultivation was conducted in 500-ml glass flasks in a JEIO TECH SL-600 incubated shaker (JEIO TECH, Korea) at $100 \mathrm{rpm}$, in the automated fermentation complex BioFlo 115 "New Brunswick Scientific" (USA), with a volume of fermentation vessel 8-12 L with a working volume of 1-3 L culture. Cultivation of the strain in the fermenter was carried out in a regime with glucose inflow, without stirring the culture medium, but with barbatozh. For air supply, an air pump of the brand EL-200 with a capacity of $9 \mathrm{~m}^{3} / \mathrm{h}$ with a head of 19.6 $\mathrm{kPa}$ was used.

Glucose concentration was determined using the "Glucose - FKD" kit, which contained chromogenic enzyme substrate and a calibrator (a glucose solution of a known concentration). Optical densities of the study sample and calibration sample were compared photometrically with the optical density of the blank, with optical path length $10 \mathrm{~mm}$ at wavelength $490 \mathrm{~nm}$.

$\mathrm{BC}$ yields in different modes of cultivation were compared by measuring the weight of the cellulose dried to constant weight, the pellicle thickness, and the amount of carbon substrate consumed. The total BC yield (g/L) and biosynthesis productivity for different fermentation processes were calculated using conventional methods. The BC yield was evaluated as the weight of dry cellulose per liter of medium $(\mathrm{g} / \mathrm{L})$; production performance $-\mathrm{P}=\mathrm{g} / \mathrm{L} \cdot \mathrm{day}$. To measure it, $\mathrm{BC}$ samples were dried at $45^{\circ} \mathrm{C}$ for 3 days until constant weight was obtained. The dried $\mathrm{BC}$ pellicles were weighed on the Adventurer OH-AR2140 analytical balance (Ohaus, Switzerland).

2.3. A study of physicochemical properties of BC

The synthesized BC was separated from the culture fluid and purified in a $0.5 \% \mathrm{NaOH}$ solution for $24 \mathrm{~h}$ at $25-27^{\circ} \mathrm{C}$. Then, cellulose was placed in a $0.5 \%$ solution of hydrochloric acid for $24 \mathrm{~h}$ for neutralization and afterwards rinsed in distilled water until $\mathrm{pH}$ 7. The $\mathrm{BC}$ pellicles were stored in sterile solution or air dried until they reached a stable weight.

Chemical composition of $\mathrm{BC}$ was analyzed by determining $\mathrm{C} / \mathrm{O} / \mathrm{N}$ using a Flash EA $1112 \mathrm{CN}$ analyzer (NEOLAB Ltd., Italy); analysis for major and trace elements was performed with an iCAP 6000 inductively coupled plasma emission spectrometer (Thermo Scientific, U.S.) after wet mineralization of cellulose samples with a mixture of perchloric and nitric acids.

Thermal analysis of cellulose samples was performed using a DSC-1 differential scanning calorimeter (METTLER TOLEDO, Switzerland). Powdered samples ( $4.0 \pm 0.2 \mathrm{mg}$ each) were placed into the aluminum crucible and compressed prior to measurement. Every sample was measured at least 3 times. Samples were preheated to $60^{\circ} \mathrm{C}$ and cooled to $25^{\circ} \mathrm{C}$. The samples were heated to temperatures from $25^{\circ} \mathrm{C}$ to $300^{\circ} \mathrm{C}$, at $5^{\circ} \mathrm{C} \times$ min- 1 (measurement precision $1.5^{\circ} \mathrm{C}$ ); melting point $(\mathrm{Tm})$ and thermal decomposition temperature $(\mathrm{Td})$ were determined from exothermal peaks in thermograms. The thermograms were analyzed using the STARe v11.0 software.

$\mathrm{X}$-Ray structure analysis and determination of crystallinity of BC were performed employing a D8 ADVANCE X-Ray powder diffractometer equipped with a VANTEC fast linear detector, using CuKa radiation (Bruker, AXS, Germany). In order to determine the crystallinity $(\mathrm{Cx})$ of $\mathrm{BC}$, the spectra were collected from a Vantec high-speed detector, with exposure time of 3000 . The detector was operated at $40 \mathrm{kV}$ and $40 \mathrm{~mA}$.

The microstructure of the surface of BC pellicles was analyzed using scanning electron microscopy (S 5500, Hitachi, Japan). Prior to the analysis, the pellicles were freeze-dried in an ALPHA 1-2/LD freeze dryer (Martin Christ GmbH, Germany) for $24 \mathrm{~h}$. Samples $(5 \times 5 \mathrm{~mm})$ were placed onto the sample stage and sputter-coated with gold, using an Emitech K575X sputter coater $(10 \mathrm{~mA}, 2 \times 40 \mathrm{~s})$. Fiber diameters were measured by analyzing SEM images with image analysis program Image Processing and Data Analysis in Java (ImageJ). The diameters of 50 individual ultrafine fibers were then measured in each SEM micrograph. Diameters were analyzed in 10 fields of SEM images in triplicate. 


\subsection{A study of physical and mechanical properties of $\mathrm{BC}$}

Physical and mechanical properties of the wet $\mathrm{BC}$ pellicles were investigated using an Instron 5565 electromechanical tensile testing machine (U.K.). Samples were maintained at ambient temperature in a laminar cabinet for at least two weeks to reach equilibrium crystallization. At least five samples were tested for each type of pellicles. Measurements were conducted at ambient temperature; the clamping length of the samples was $30 \mathrm{~mm}$. The speed of the crosshead was $3 \mathrm{~mm} / \mathrm{min}$ at ambient temperature. Young's modulus (E, MPa) and elongation at break $(\varepsilon, \%)$ were automatically calculated by the Instron software (Bluehill 2, Elancourt, France). To obtain Young's modulus, the software calculated the slope of each stress-strain curve in its elastic deformation region. Measurement error did not exceed $10 \%$.

2.5. A study of BC biocompatibility in cell culture in vitro

The ability of BC pellicles to facilitate cell attachment was studied using NIH 3T3 mouse fibroblast cells. $\mathrm{BC}$ pellicles were sterilized by autoclaving them in a phosphate-buffer solution for $15 \mathrm{~min}$ at $121^{\circ} \mathrm{C}$. Cells were seeded into 24-well cell culture plates (Greiner Bio-One, U.S.) $(1 \times 103 \mathrm{cells} / \mathrm{ml}$ per well). Cells were cultured in DMEM medium supplemented with $10 \%$ fetal bovine serum and a solution of antibiotics (streptomycin $100 \mu \mathrm{g} / \mathrm{ml}$, penicillin $100 \mathrm{IU} / \mathrm{ml}$ ) (Sigma) in a $\mathrm{CO}_{2}$ incubator with $\mathrm{CO}_{2}$ level maintained at $5 \%$, at a temperature of $37{ }^{\circ} \mathrm{C}$. The medium was replaced every three days. Morphology of cells, attached to the pellicle surface, was determined using DAPI and FITC fluorescent dyes (DNA and cytoplasm markers), and by using scanning electron microscopy. For this, pellicles with attached cells were rinsed in phosphate buffer to remove nutrient medium and fixed in formalin for $24 \mathrm{~h}$ at ambient temperature. Then, the pellicles were rinsed with increasing concentrations of ethanol and, finally, with absolute ethanol, and then freeze dried. The images of cells on the pellicles were taken with a TM-3000 electron microscope (Hitachi, Japan). Cell viability and metabolic activity were evaluated using MTT assay at day 7 after cell seeding onto pellicles. Reagents were purchased from Sigma-Aldrich. A 5\% MTT solution $(50 \mu 1)$ and complete nutrient medium $(950 \mu \mathrm{l})$ were added to each well of the culture plate. After $3.5 \mathrm{~h}$ incubation, the medium and MTT were replaced by DMSO to dissolve MTT-formazan crystals. After $30 \mathrm{~min}$, the supernatant was transferred to the 96-well plate, and optical density of the samples was measured at wavelength $540 \mathrm{~nm}$, using a Bio-Rad 680 microplate reader (Bio-Rad LABORATORIES Inc., U.S.). All measurements were performed in triplicate. The number of viable cells was determined from the calibration graph.

2.6. Statistics

Statistical analysis of the results was performed by conventional methods, using the standard software package of Microsoft Excel. Arithmetic means and standard deviations were found.

\section{Results and discussion}

\subsection{Biosynthesis of $\mathrm{BC}$ in the K. xylinus B-12068 culture}

The production of BC in the culture of Komagataeibacter xylinus B-12068 at various carbon sources and in the modification of culture parameters was studied. Fig. 1a shows results of evaluating the ability of the strain K. xylinus B-12068 to synthesize cellulose under static conditions in glass flasks at a temperature of $30^{\circ} \mathrm{C}$ and initial $\mathrm{pH}$ of 6.0 in the HS medium with varied carbon sources. The highest BC yield (about $2.2 \mathrm{~g} / \mathrm{L}$ ) was obtained in the experiment with the K. xylinus B-12068 cells cultivated for 7 days in the HS medium containing glucose (Fig. 1a). The $\mathrm{BC}$ yield in the media with sucrose and galactose was somewhat lower -1.6 and $1.4 \mathrm{~g} / \mathrm{L}$, respectively. On the media containing maltose and mannitol, $\mathrm{BC}$ production was very low, about $0.1-0.2 \mathrm{~g} / \mathrm{L}$, i.e. these carbon sources were not suitable for production of bacterial cellulose by this strain. The physiological glucose range for this strain is rather wide; $\mathrm{K}$. xylinus B-12068 growth and BC production were inhibited at glucose concentration in the culture medium higher than $25 \%(\mathrm{w} / \mathrm{v})$. Mohammadkazemi, Azin, and Ashori (2015) reported a study of the effects of carbon sources and nitrogen concentration in the culture medium on BC production. Castro et al. (2012) also showed the effect of the carbon source on BC production: the BC yield from glucose was the highest $(3 \mathrm{~g} / \mathrm{L})$ while the medium containing sucrose yielded $2 \mathrm{~g} / \mathrm{L}$, and the media with fructose and mannitol - no more than $0.4 \mathrm{~g} / \mathrm{L}$. These data are consistent with the results reported in another study, which showed that such carbon sources as maltose, cellobiose, xylose, and galactose were less suitable for BC production by Acetobacter xylinum than glucose (Surma-Ślusarska, Presler, \& Danielewicz, 2008). 
(a)

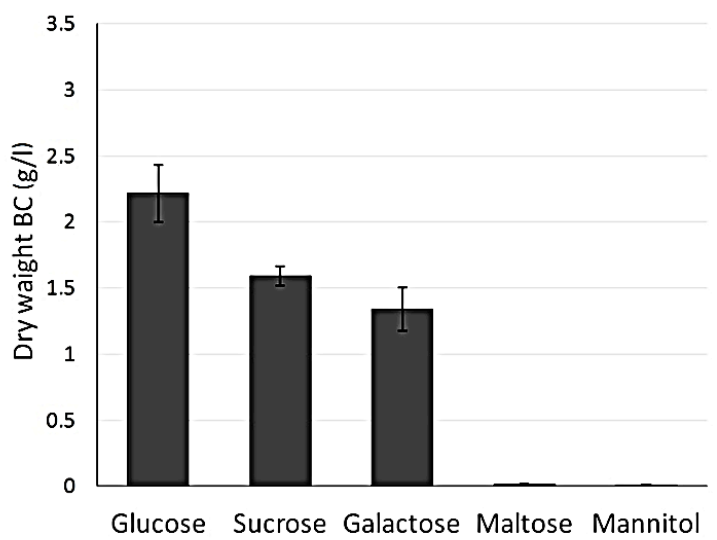

(c)

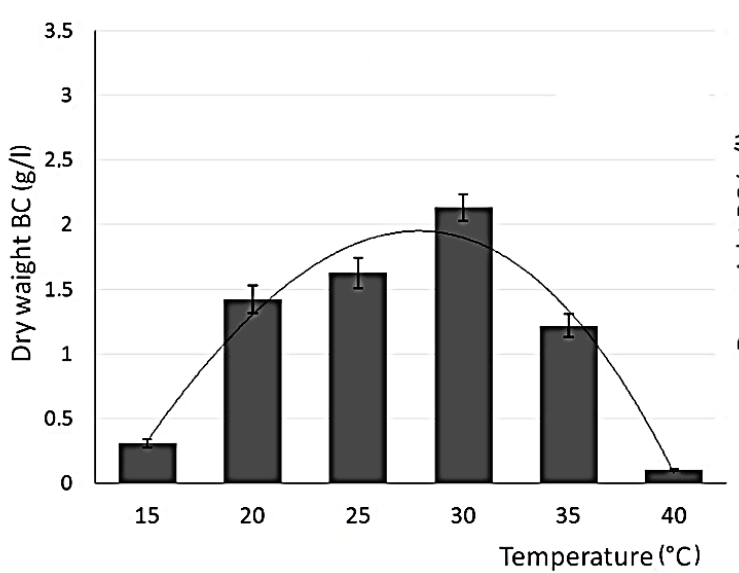

(b)

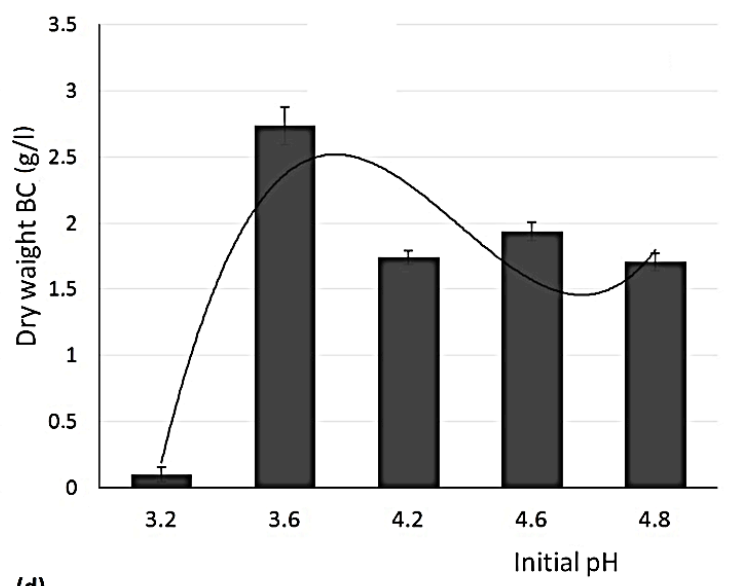

(d)

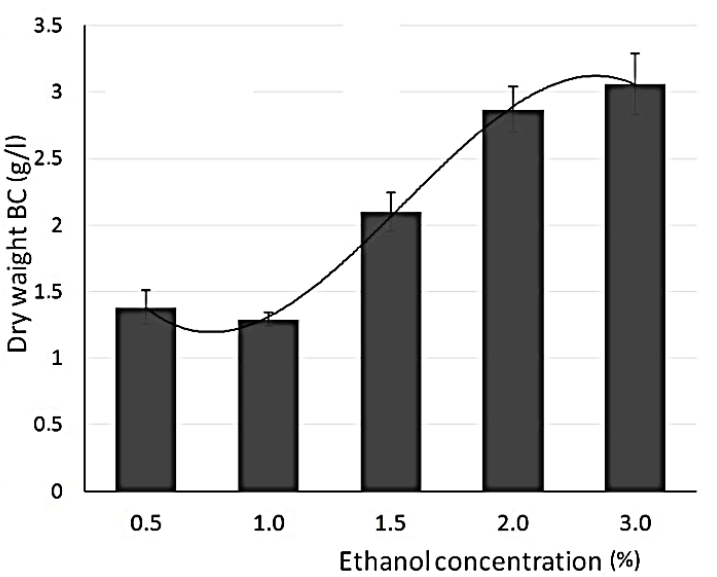

Fig. 1. Effects of carbon source (a), pH (b), temperature (c), and ethanol concentration on cellulose yield in Komagataeibacter xylinus B-12068 culture $(\mathrm{g} / \mathrm{L})$

As $\mathrm{BC}$ production is influenced not only by carbon sources but also by agitation conditions, the medium volume to surface area ratio, $\mathrm{pH}$ of the medium, and addition of the secondary carbon substrates to the medium (Pokalwar, Mishra, \& Manwar, 2010; Ruka, Simon, \& Dean, 2012; Fu, Zhang, \& Yang, 2013; Keshk, 2014; Li et al., 2015), we investigated cellulose production under varied conditions of $K$. xylinus $B-12068$ cultivation. Fig. 1b shows, how the initial $\mathrm{pH}$ value influenced cellulose production by the strain. The physiological $\mathrm{pH}$ range for $K$. xylinus $B-12068$ is between 3.2 and 5.0. The trend in the graph indicates the optimal $\mathrm{pH}$ range for BC biosynthesis, which is very narrow - between 3.6 and 4.0. The highest BC yield from the standard HS medium $(2.73 \mathrm{~g} / \mathrm{L})$ was obtained at $\mathrm{pH}$ 3.6. When K. xylinus $B-12068$ cells were cultivated in the glucose-enriched medium, the initial $\mathrm{pH}$ value of 6.0 dropped to 3.4 after 7 days of cultivation due to accumulation of products of glucose oxidation, mainly, gluconic acid. As K. xylinus $B-12068$ was found to be acid tolerant, the $\mathrm{pH}$ of the medium, which decreased during cultivation, did not need to be adjusted. During cultivation of $K$. xylinus B-12068 in the media containing such poorly utilized carbon sources as maltose and mannitol, $\mathrm{pH}$ did not decrease considerably - only to 5.4-5.8. Different strains of acetic acid bacteria show varying acid tolerance. In a study by Castro et al. (2012), the highest BC yields were obtained in G.medellensis culture at $\mathrm{pH} 3.5$ (up to $4.5 \mathrm{~g} / \mathrm{L}$ ). The ability of bacteria to synthesize $\mathrm{BC}$ at low $\mathrm{pH}$ values can be used to reduce the risk of contamination of the commercial strain by foreign microflora.

The effect of the temperature of the K. xylinus B-12068 culture medium on BC production is shown in Fig. $1 \mathrm{c}$, suggesting that the optimal temperature range for cell growth and $\mathrm{BC}$ production is rather narrow $-28-30^{\circ} \mathrm{C}$, while the physiological temperature range is wide $\left(20-37^{\circ} \mathrm{C}\right)$.

Based on the data suggesting that acetic acid bacteria are capable of oxidizing ethanol and that in some cases, ethanol enhances the productivity of BC, e.g. in G. hansenii culture (Park, Jung, \& Park, 2003), we investigated the effect of ethanol as a secondary substrate on BC production by K. xylinus B-12068 cultivated in the HS medium enriched with glucose (Fig. 1d). The increase in ethanol concentration from 0.5 to $3.0 \%$ (v/v) resulted in an increase in cellulose production, from 1.38 to $3.06 \mathrm{~g} / \mathrm{L}$. The highest $\mathrm{BC}$ yields were obtained at ethanol concentration of $3 \%$.

As glucose was determined as the best substrate for K. xylinus $B-12068$, it was used as carbon substrate in the subsequent experiments. Results of the comparative study of the effects of cultivation conditions on $\mathrm{BC}$ production are given in Table 1. 
When the strain was grown on the surface of glucose-enriched HS medium $(100 \mathrm{ml}$, the layer of the medium 2.0 $\pm 0.1-\mathrm{cm}$ high) under static conditions, the BC productivity and the effectiveness of substrate (glucose) consumption were the lowest. Under agitated conditions, BC yield was 1.6 times higher than under static ones. Modification of HS medium by adding ethanol concentration of $3 \%(\mathrm{v} / \mathrm{v})$ and decreasing the initial $\mathrm{pH}$ value to 3.9 enhanced BC productivity of K. xylinus $B-12068$ to $0.97-1.13 \mathrm{~g} / \mathrm{L} \cdot$ day under static conditions and to $0.89 \mathrm{~g} / \mathrm{L} \cdot \mathrm{day}$ under shaking. The efficiency of ВC production (выход по субстрату) on modified medium varied within a narrow range - between 37.1 до $39.8 \%$ glucose. The use of citrate or acetate to achieve the initial value of $\mathrm{pH}$ of the medium did not cause any significant changes in BC production (Table 1). The highest productivity of the culture was obtained on glucose in a static culture on HS modified medium (glucose + ethanol) at a layer height of $25 \mathrm{~mL}$; for 7 days the harvest of the BC was $17 \mathrm{~g} / \mathrm{L}$; productivity of the process was $2.43 \mathrm{~g} / \mathrm{L} \cdot$ day.

An important result was obtained by replacing glycerol as the main C-substrate with glycerol. When cultured by the surface method in $250 \mathrm{ml}$ flasks per $100 \mathrm{ml}$ of standard HS medium, the BC output after 7 days was $2.08 \pm 0.17 \mathrm{~g} / 1$, relatively to the previously obtained $1.77 \pm 0.33 \mathrm{~g} / \mathrm{L}$ on glucose. With a decrease in the height of the medium layer to $50 \pm 1 \mathrm{~mm}$, the output of the $\mathrm{BC}$ for 7 days increased by $23.2 \mathrm{~g} / \mathrm{L}$; productivity $-\mathrm{up}$ to $3.3 \mathrm{~g} / \mathrm{L}$ day.

Table 1

Bacterial cellulose production on standard and modified Hestrin-Schramm media in different volumes

\begin{tabular}{|c|c|c|}
\hline $\begin{array}{l}\text { Culture conditions, } \\
\text { Carbon source, medium volume }\end{array}$ & $\mathrm{BC}(\mathrm{g} / \mathrm{l})$ & $\mathrm{P}=\mathrm{g} / \mathrm{L} \cdot$ day \\
\hline \multicolumn{3}{|l|}{ Static conditions } \\
\hline Flask, HS standard medium (glucose), $100 \mathrm{ml}$ & 1.7 & $8.3 \quad 0.24$ \\
\hline Flask, HS modified medium (glucose+ethanol), $100 \mathrm{ml}$ & 7.9 & $39.3 \quad 1.13$ \\
\hline Petri dishes, HS standard medium (glucose), $25 \mathrm{ml}$ & 4.3 & $21.4 \quad 0.61$ \\
\hline Petri dishes, HS modified medium (glucose+ethanol), $25 \mathrm{ml}$ & 17.0 & $85.0 \quad 2.43$ \\
\hline Glass tray, HS modified medium (glucose+ethanol) $500 \mathrm{ml}$ & 6.8 & $39.8 \quad 0.97$ \\
\hline Petri dishes, HS modified medium (глицерин), $25 \mathrm{ml}$ & 23.2 & ??? 3.30 \\
\hline \multicolumn{3}{|l|}{ Agitated conditions } \\
\hline Flask, standard medium (glucose), $150 \mathrm{ml}$ & 2.8 & $16.9 \quad 0.41$ \\
\hline Flask, modified medium (glucose+ethanol), $150 \mathrm{ml}$ & 6.2 & 37.10 .89 \\
\hline
\end{tabular}

The use of larger bulbs (3-5 liters) and fermentation vessels in the form of trays allowed us to scale the process and gave us opportunity to product BC films of various sizes. (Fig.2).
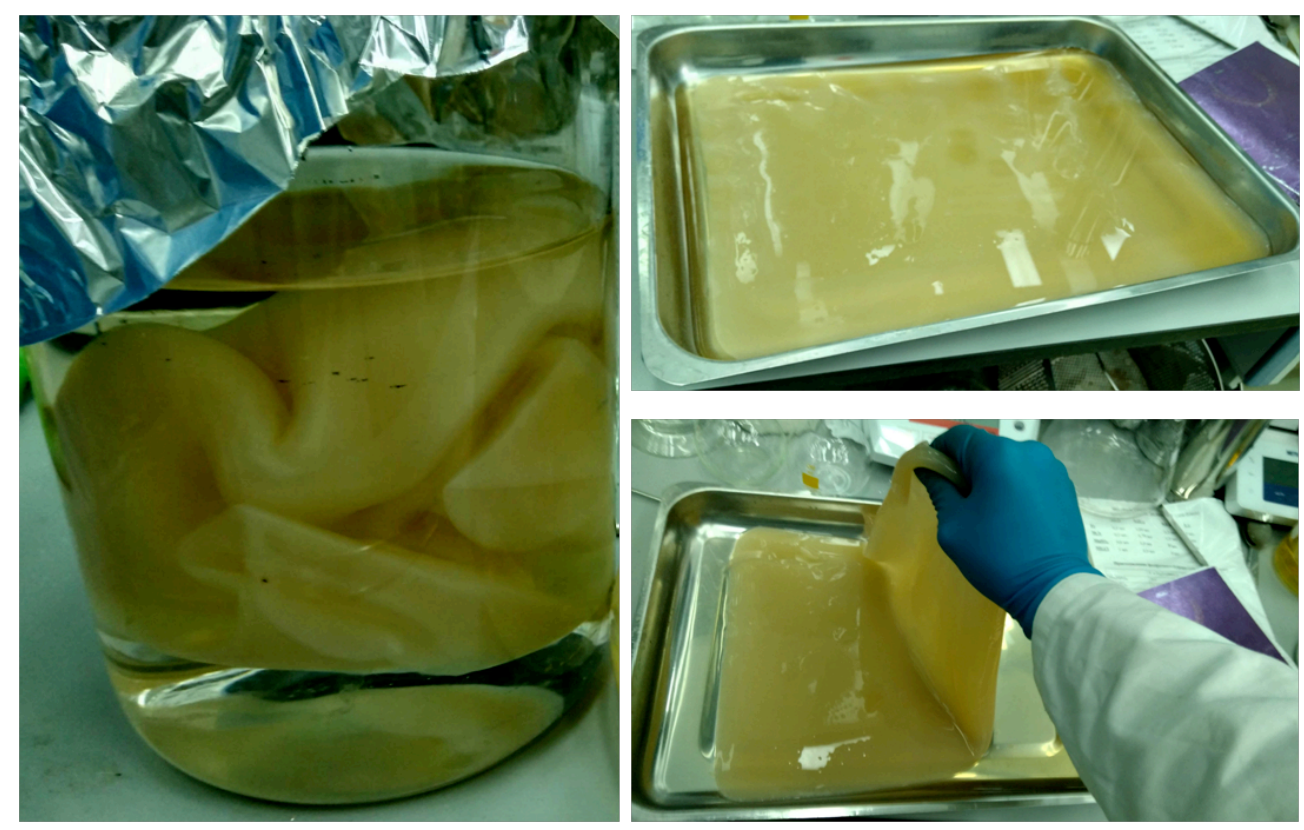

Fig. 2 - The results of scaling of the BC-synthesis in a static surface culture 
Under agitated conditions, however, in contrast to the static culture, cellulose did not form a pellicle at the air/culture medium interface but was shaped as spheres, filaments, and fibers distributed over the volume of the culture medium (Fig 3).

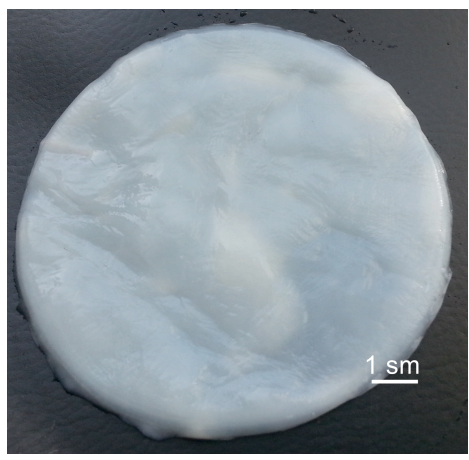

a

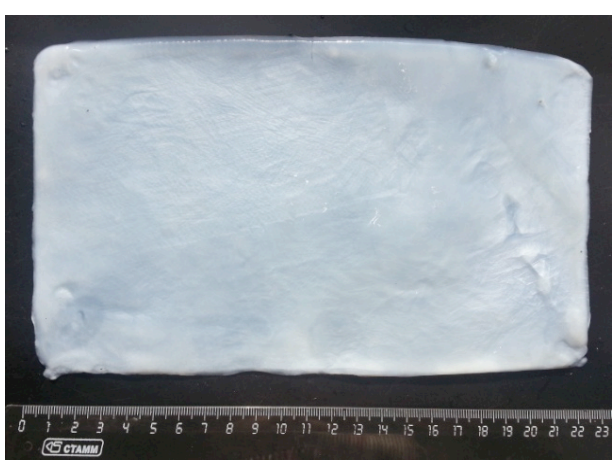

B

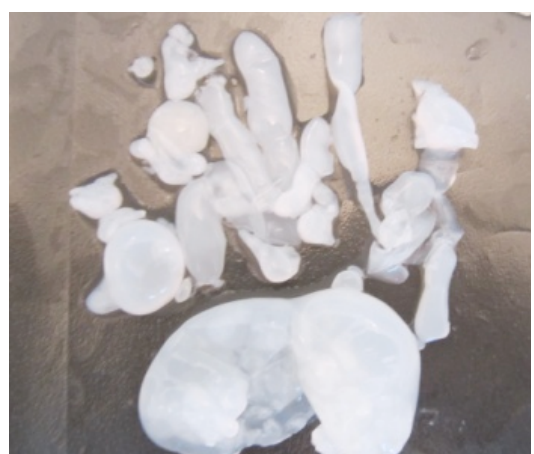

C

Fig 3. Photo of BC, synthesized in the culture of Komagataeibacter xylinus B-12068 under surface static conditions ( $\mathrm{a}$ and $\mathrm{b})$, and in a deep culture under agitated conditions (c)

The available data on the effect of culture conditions (static or agitated culture) are contradictory. Some data suggested (Schramm \& Hestrin, 1954) that cellulose did not form pellicles in the agitated media with G. xylinus culture but accumulated as irregular spherical pellets in the medium; cellulose yield was found to decrease. Ruka, Simon, and Dean (2012), however, showed that when G. xylinus was grown under static and agitated conditions in the high-production Yamanaka-mannitol, Zhou-sucrose, and Zhou-mannitol media, no difference was observed between BC yields. Ruka, Simon, and Dean (2012) varied the sizes of fermentation vessels and the volumes of the media in them and found that the highest cellulose production was obtained in the bioreactor with the largest surface area. The use of greater volumes of the medium resulted in higher cellulose yields, but that also increased production cost and time. Moreover, the layer of the medium had to be sufficiently thick for cellulose to be completely immersed in it during the production process. Authors of another study (Pa'e, Zahan, \& Muhamad, 2011) compared BC yields in the static culture of A. xylinum and in the agitated culture by using a Rotary Discs Reactor, RDR, and found an $80.77 \%$ difference, with the BC production being considerably higher in the bioreactor than in the static culture.

In the present study, the highest BC yield $17.0-23.2 \mathrm{~g} / \mathrm{L}$ or $2.4-3.3 \mathrm{~g} / 1 \cdot$ day was observed in the experiment with K. xylinus B-12068 grown in Petri dishes containing $20 \mathrm{ml}$ of the medium (the medium layer being $0.5 \pm 0.1 \mathrm{~cm}$ thick). In Petri dishes, the volume of the medium was four times smaller than in the flasks but the surface area was the same as in the flasks $(60 \pm 1 \mathrm{~cm} 2)$, and the amount of the substrate (glucose) was 2.2-2.6 times smaller (Table 1). These results are in good agreement with the data in the study by Ruka, Simon, and Dean (2012), showing that the lower volume of the nutrient medium in the vessel did not decrease BC production but increased the efficiency of utilization of carbon substrate.

Thus, in the present study, high yields of BC were obtained from the culture of K. xylinus B-12068-a new strain of acetic acid bacteria.

3.3. Physicochemical and mechanical properties of BC

Elemental analysis of $\mathrm{BC}$ was done after purification of the samples. Carbon and hydrogen constituted $44.2 \pm 1.6$ and $6.3 \pm 0.25 \%$, respectively. This is in good agreement with the data reported by a number of authors (Klemm, Schumann, Udhardt, \& Marsch, 2001; Yoon, Jin, Kook, \& Pyun, 2006). Cellulose also contained nitrogen $(0.39 \pm 0.04 \%)$. Chemical elements, contained in the BC, were determined by emission spectrometry, and the major elements were $\mathrm{Na}, \mathrm{K}, \mathrm{P}, \mathrm{Ca}$, and $\mathrm{S}$.

To determine physicochemical properties of the $\mathrm{BC}$, we used pellicles that had been treated to remove microorganisms and dried. The pellicles produced in surface culture on standard and modified HS media were removed after 7 days of incubation at $30{ }^{\circ} \mathrm{C}$. The thickness of the dry pellicles was $1.8 \pm 0.2 \mathrm{~mm}$ and the density $0.15 \pm 0.01 \mathrm{~cm} 3$.

Natural cellulose fibers (wood and cotton cellulose) show degrees of crystallinity of $65-70 \%$ (Castro et al., 2011; Keshk, 2014); different authors report degrees of crystallinity of BC varying between 46.7 and $91.62 \%$. The $\mathrm{Cx}$ value of $\mathrm{BC}$ was found to be related to both carbon source used and cultivation conditions (Mohammadkazemi, Azin, \& Ashori, 2015; Zheng et al., 2015; Huang et al., 2016). The BC samples synthesized by the K. xylinus strain showed considerably different degrees of crystallinity: between 45 and 89\% (Fig. 4a). The BC synthesized in the HS medium enriched with galactose had the lowest $\mathrm{Cx}$ value $-45 \%$ (Table 2). The $\mathrm{BC}$ produced on the media containing glucose and sucrose and on the medium with ethanol showed intermediate degrees of crystallinity (63- 
$68 \%$ ). The highest degree of crystallinity ( $85-89 \%$ ) was exhibited by the BC samples produced in the medium with the initial $\mathrm{pH}$ of 3.6 in the presence of citrate or acetate.

Table 2

Bacterial cellulose production on standard and modified Hestrin-Schramm media in different volumes.

\begin{tabular}{llcll}
\hline Bacterial cellulose production on standard and modified Hestrin-Schramm media in different volumes. \\
Sample characterization & $\mathrm{X}(\%)$ & Tdegr $\left({ }^{\circ} \mathrm{C}\right)$ & $\begin{array}{l}\text { Young's } \\
\text { modulus } \\
(\mathrm{MPa})\end{array}$ & $\begin{array}{l}\text { Elongation } \\
\text { break } \\
(\%)\end{array}$ \\
\hline HS medium + galactose & 45 & 284 & 5.13 & 10.14 \\
HS medium + sucrose & 63 & 220 & 5.33 & 13.30 \\
HS medium + glucose & 65 & 249 & 3.73 & 12.54 \\
HS medium + glucose + ethanol & 68 & 270 & 4.29 & 15.18 \\
HS medium + glucose + citrate & 85 & 278 & 3.43 & 12.10 \\
HS medium + glucose + acetate & 89 & 252 & 5.54 & 13.00 \\
& & & & \\
\hline
\end{tabular}

The maximum decomposition temperature is a criterion of thermal stability of the material. Thermal decomposition behavior is determined by several structural parameters such as molecular weight, degree of crystallinity, and fiber orientation (Barud et al., 2007; Vazquez, Foresti, Cerrutti, \& Galvagno, 2013). Results of DTA (Fig. 4b) showed different degrees of thermal stability of BC samples. As the decomposition region has no distinct peaks, the parameter determining thermal stability is the onset temperature of decomposition (Tonset). The $\mathrm{BC}$ synthesized in the galactose-enriched medium showed the highest thermal stability (Tonset $-284{ }^{\circ} \mathrm{C}$ ). The BC synthesized from sucrose had the lowest Tonset $\left(220^{\circ} \mathrm{C}\right)$. For all samples, we observed the presence of two subregions in the decomposition region. The first sub-region corresponded to the temperature interval between $220^{\circ} \mathrm{C}$ and $285^{\circ} \mathrm{C}$. In this sub-region, we observed an insignificant weight loss. The second sub-region corresponded to the temperature interval between $360{ }^{\circ} \mathrm{C}$ and $430{ }^{\circ} \mathrm{C}$. In that sub-region, the weight loss was more significant, as thermal decomposition processes became more intense. The thermal stability of $\mathrm{BC}$ was reported in many studies. Mohammadkazemi, Azin, and Ashori (2015) studied thermal behavior of BC and showed that thermal decomposition could start at temperatures between 200 and $250^{\circ} \mathrm{C}$, although more noticeable decomposition, with the weight loss reaching $70-80 \%$, was observed at 360-390 ${ }^{\circ} \mathrm{C}$. Other authors (Surma-Ślusarska, Presler, \& Danielewicz, 2008) also observed $\mathrm{BC}$ weight loss at a temperature of $300{ }^{\circ} \mathrm{C}$ and a more intense decomposition process at $350-370{ }^{\circ} \mathrm{C}$. 


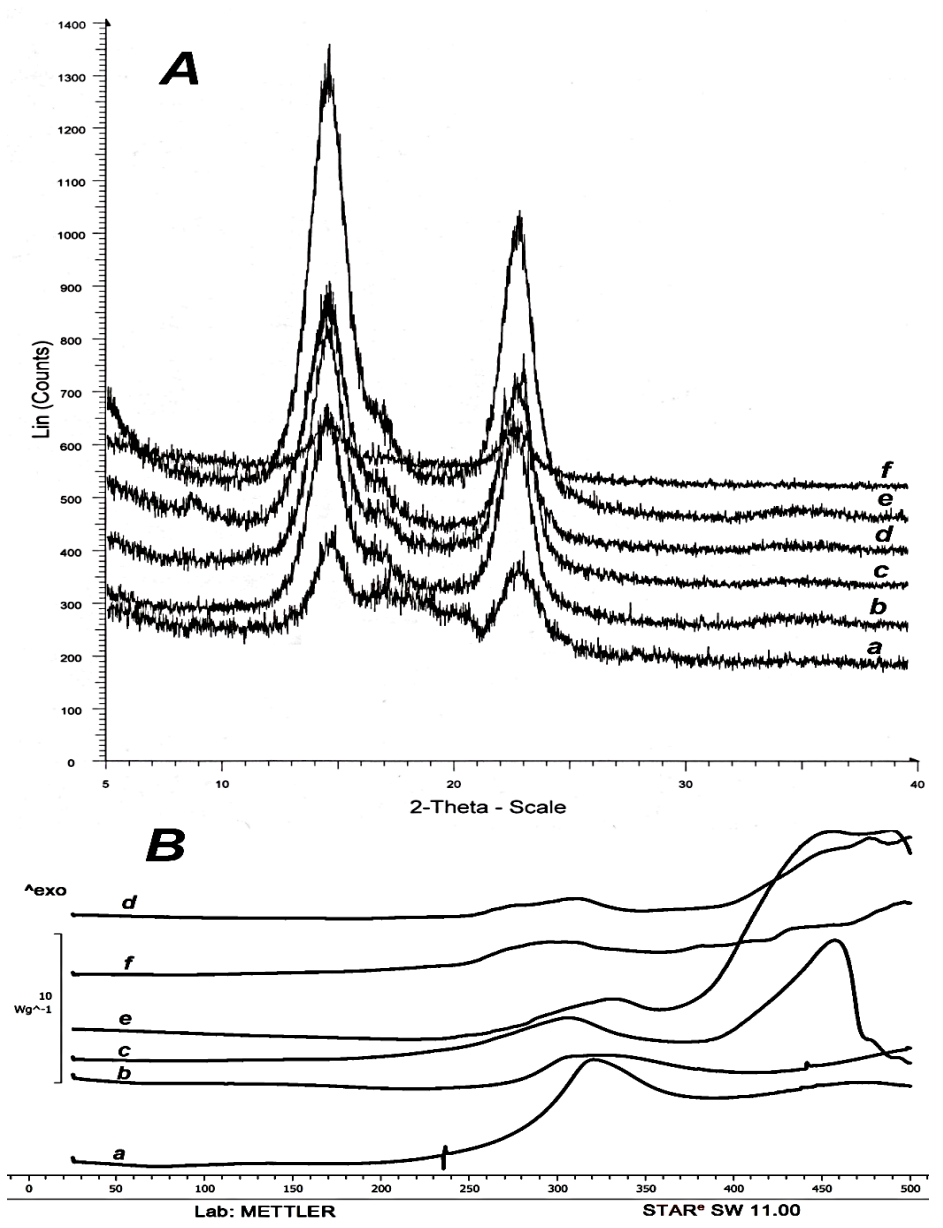

Fig. 4. X-ray diffraction diagrams (A) indicating the main reflexes corresponding to cellulose crystal I $\alpha$ with the calculated parameters $a=6.72, b=5.96, c=10.40 \AA ; \alpha=118.1^{\circ}, \beta=114.8^{\circ}, \gamma=80.4^{\circ}$ and axis c parallel to the molecular axis. Positions of these reflexes differ between samples, e.g., (100) varies between $14.24^{\circ}$ and $14.52^{\circ}$, and DTA (B) of bacterial cellulose produced by $K$. xylinus $B-2068$ on HS media under different conditions: a galactose; $\mathrm{b}$ - sucrose, $\mathrm{c}-$ glucose; $\mathrm{d}-$ initial $\mathrm{pH}=3.6$ in the presence of citrate; $\mathrm{e}-$ initial $\mathrm{pH}=3.6$ in the presence of acetate; $\mathrm{f}$ - addition of ethanol $(3 \%)$

The ultrastructure and size of fibrils is a critical factor that determines the unique properties of bacterial cellulose. SEM images of the surface microstructure of BC pellicles (Fig. 5) show that BC pellicles are layered nets of different densities composed of randomly oriented cellulose microfibrils. This is typical BC morphology, which was previously described by Yamanaka, and Sugiyama (2000). The diameter of microfibrils of the BC specimens varied between 25 and $115 \mathrm{~nm}$. The BC microfibrils with the smallest diameter $(25 \mathrm{~nm})$ were synthesized in the galactose-enriched medium, with the average diameter being $40 \mathrm{~nm}$ (Fig. 5a). The smallest diameter of microfibrils of the $\mathrm{BC}$ produced in the glucose-enriched media supplemented with ethanol was about $30 \mathrm{~nm}$, and the average diameter varied between 45 and $47 \mathrm{~nm}$ (Fig. 5b, c). The largest-diameter microfibrils $(115 \mathrm{~nm})$ were found in the $\mathrm{BC}$ synthesized in the sucrose-enriched medium, and the average diameter was $74 \mathrm{~nm}$ (Fig. 5d). Comparison of the results showed considerable differences in the ranges of microfibril diameters between the $\mathrm{BC}$ produced in galactose- and sucrose-enriched media (70 and $80 \mathrm{~nm}$, respectively) and the BC synthesized in glucose-enriched media supplemented with ethanol $(50 \mathrm{~nm})$. A layered structure (spatial separation of microfibrils in different layers) was observed only in the $\mathrm{BC}$ synthesized from glucose, with the invariant distribution of microfibril diameters between the layers. 

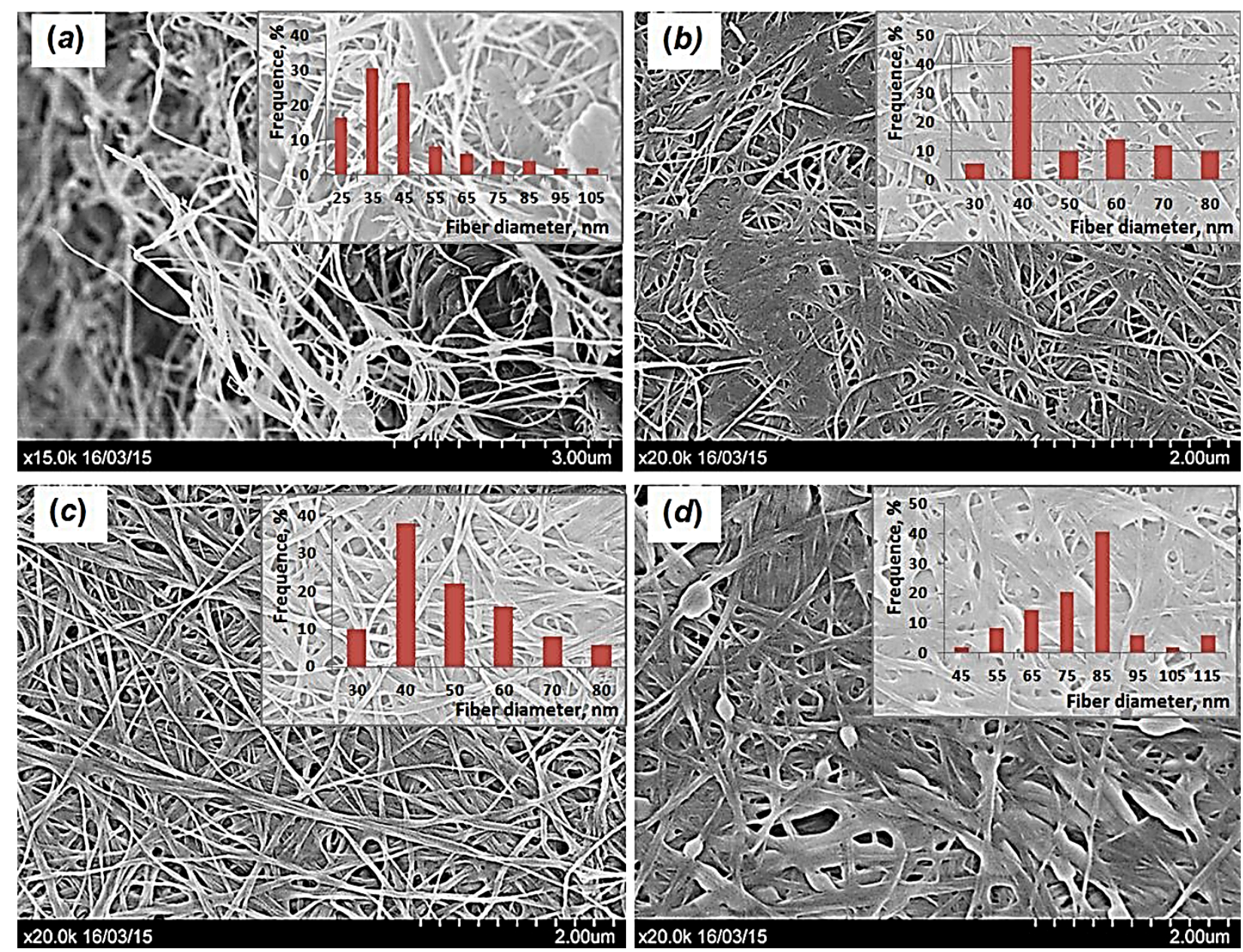

Fig. 5. SEM images of bacterial cellulose produced by K. xylinus B-12068: a - galactose, b-glucose, c - glucose+ ethanol, $d$ - sucrose.

Huang et al. (2016) observed differences in the microstructure of BC pellicles synthesized by Gluconacetobacter xylinus after 3 to 10 days of fermentation in lipid wastewater. The literature data on BC microfibril sizes differ considerably. Castro et al. (2012) reported that microfibrils in the network were randomly oriented and their diameters varied between 40 and $70 \mathrm{~nm}$. In Acatobacter xulinum culture, the composition of the culture medium, particularly the presence of ammonium citrate, influenced the diameter of cellulose microfibrils, and it varied between 3 and $14 \mathrm{~nm}$ (Li et al., 2015). Surma-Ślusarska, Presler, and Danielewicz (2008) found that smooth and oriented fibrils and fibril bundles in the BC synthesized by Acetobacter xylinum had diameters varying between 70 and $200 \mathrm{~nm}$. In a study by Ruka et al. (2012), however, the authors analyzed the microstructure of the BC synthesized by Gluconacetobacter xylinus and did not find any apparent difference in the appearance and fibril diameter, as the cellulose produced under different conditions retained its interwoven nano-sized structure.

In the study of physical and mechanical properties of wet $\mathrm{BC}$ pellicles, we evaluated their strength and elasticity. The study showed that culture conditions did not considerably influence these parameters. Young's modulus, which measures an object's resistance to being deformed elastically, varied between 3.4 and $5.5 \mathrm{MPa}$ (Table 2). Elongation at break, which measures elastic properties of BC, varied between 10 and $15 \%$.

3.4. Biocompatibility of bacterial cellulose

Biocompatibility of cellulose synthesized by K. xylinus B-12068 was studied in the culture of NIH 3T3 mouse fibroblast cells. Cell viability and metabolic condition were evaluated in MTT assay at Days 3 and 7 after cell seeding and compared with the control (polystyrene) (Fig. 6) 


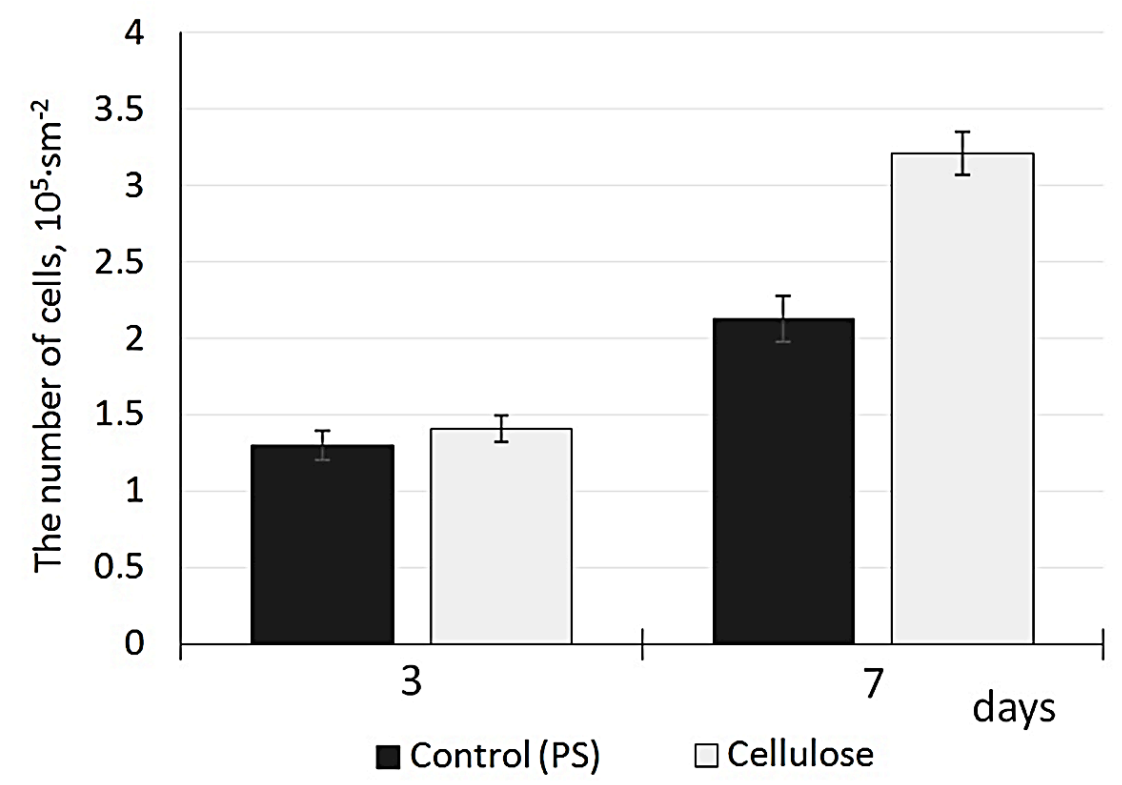

Fig. 6. MTT assay: the number of NIH 3T3 mouse fibroblasts $\left(\times 10^{5}\right.$ cells $\left.\mathrm{cm}^{-2}\right)$ on the surface of bacterial cellulose and composite of bacterial cellulose and polystyrene (control).

The BC did not cause cytotoxicity upon direct contact with fibroblasts and enabled high survival of the cells. After 3 days of cultivation, the number of viable cells on the surface of the BC scaffold did not differ significantly from their number in the control (on polystyrene). Moreover, at Day 7, the number of viable cells on $\mathrm{BC}$ was 1.4 times higher than on polystyrene: $3.21 \times 105$ cells $/ \mathrm{cm} 2$ versus $2.13 \times 105 \mathrm{cell} / \mathrm{s} / \mathrm{cm} 2$.
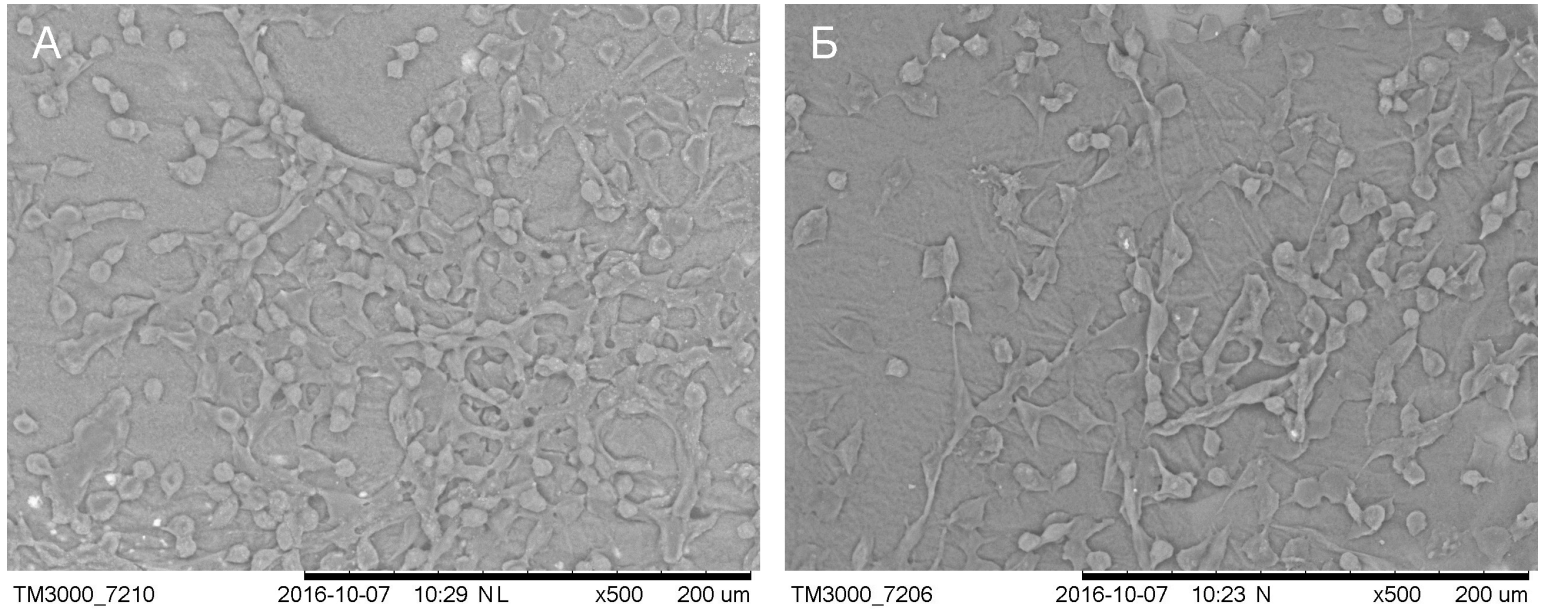

Fig. 7. SEM images of NIH $3 \mathrm{~T} 3$ mouse fibroblasts on the surface of bacterial cellulose (a) and polystyrene (b)

The morphology of fibroblasts cultivated on the surface of BC for 7 days is shown in Fig. 7. BC scaffolds clearly facilitated fibroblast adhesion. Well-spread spindle-shaped and star-shaped active cells could be seen on the surface of BC pellicles. On the control scaffold (polystyrene), the number of cells was considerably lower. These results are consistent with the data reported in other studies, which also showed that pure BC pellicles and BC composites with other polymers were biocompatible and suitable for cell technologies (Schumann et al., 2009; Barud et al., 2011; Zhijiang, Guang, \& Kim, 2011; Lin, Lien, Yeh, Yu, \& Hsu, 2013; Culebras et al., 2015).

\section{Conclusion}

In the present study, we investigated production of bacterial cellulose in the culture of a new strain, Komagataeibacter xylinus B-12068, from different carbon sources and under different culture conditions. The highest BC yield (17.0-23.2 g/L) was obtained in the modified glucose-enriched HS medium supplemented with ethanol at $30^{\circ} \mathrm{C}$ and $\mathrm{pH} 3.9$ over 7 days of cultivation. We investigated the microstructure of the cellulose and its physicochemical and mechanical properties. BC pellicles were found to facilitate adhesion and favor proliferation of cells (NIH 3 T3 mouse fibroblasts) and, thus, showed good potential as material for biomedical applications. 
Acknowledgement

The study was performed in accordance with the program of fundamental research in RAS (Project registration No. 01201351505).??????????

\section{References}

Barud, H. S., Ribeiro, C. A., Crespi, M. S., Martines, M. A. U., Dexpert-Ghys, J., Marques, R. F. C. \& Ribeiro, S. J. L. (2007). Thermal characterization of bacterial cellulose-phosphate composite membranes. Journal of Thermal Analysis and Calorimetry, 87(3), 815-818.

Barud, H. S., Souza, J. L., Santos, D. B., Crespi, M. S., Ribeiro, C. A., Messaddeq, Y., \& Ribeiro, S. J. (2011). Bacterial cellulose/poly (3-hydroxybutyrate) composite membranes. Carbohydrate Polymers, 83(3), 1279-1284.

Castro, C., Zuluaga, R., Álvarez, C., Putaux, J. L., Caro, G., Rojas, O. J., Mondragon, I., \& Gañán, P. (2012). Bacterial cellulose produced by a new acid-resistant strain of Gluconacetobacter genus. Carbohydrate polymers, 89(4), 10331037.

Castro, C., Zuluaga, R., Putaux, J. L., Caro, G., Mondragon, I., \& Ganán, P. (2011). Structural characterization of bacterial cellulose produced by Gluconacetobacter swingsii sp. from Colombian agroindustrial wastes. Carbohydrate Polymers, 84(1), 96-102.

Culebras, M., Grande, C. J., Torres, F. G., Troncoso, O. P., Gomez, C. M., \& Bañó, M. C. (2015). Optimization of cell growth on bacterial cellulose by adsorption of collagen and poly-L-lysine. International Journal of Polymeric Materials and Polymeric Biomaterials, 64(8), 411-415.

Fu, L., Zhang, J., \& Yang, G. (2013). Present status and applications of bacterial cellulose-based materials for skin tissue repair. Carbohydrate polymers, 92(2), 1432-1442.

Hestrin, S. \& Schramm, M. (1954). Synthesis of cellulose by Acetobacter xylinum. 2. Preparation of freeze-dried cells capable of polymerizing glucose to cellulose. Biochemical Journal, 58(2), 345.

Huang, C., Guo, H. J., Xiong, L., Wang, B., Shi, S. L., Chen, X. F., ... \& Chen, X. D. (2016). Using wastewater after lipid fermentation as substrate for bacterial cellulose production by Gluconacetobacter xylinus. Carbohydrate polymers, 136, 198-202.

Hungund, B. S. \& Gupta, S. G. (2013). Strain improvement of Gluconacetobacter xylinus NCIM 2526 for bacterial cellulose production. African Journal of Biotechnology, 9(32), 5170-5172.

Keshk, S. M. (2014). Bacterial cellulose production and its industrial applications. Journal of Bioprocessing \& Biotechniques, 4(2), 1.

Klemm, D., Schumann, D., Udhardt, U., \& Marsch, S. (2001). Bacterial synthesized cellulose - artificial blood vessels for microsurgery. Progress in Polymer Science, 26(9), 1561-1603.

Li, Z., Wang, L., Hua, J., Jia, S., Zhang, J., \& Liu, H. (2015). Production of nano bacterial cellulose from waste water of candied jujube-processing industry using Acetobacter xylinum. Carbohydrate polymers, 120, 115-119.

Lin, W. C., Lien, C. C., Yeh, H. J., Yu, C. M., \& Hsu, S. H. (2013). Bacterial cellulose and bacterial cellulose-chitosan membranes for wound dressing applications. Carbohydrate polymers, 94(1), 603-611.

Ma et al., 2010 Ma, X., Wang, R. M., Guan, F. M., \& Wang, T. F. (2010). Artificial dura mater made from bacterial cellulose and polyvinyl alcohol. CN Patent ZL200710015537, 5.

Mohammadkazemi, F., Azin, M., \& Ashori, A. (2015). Production of bacterial cellulose using different carbon sources and culture media. Carbohydrate polymers, 117, 518-523.

Pa'e, N., Zahan, K. A., \& Muhamad, I. I. (2011). Production of biopolymer from Acetobacter xylinum using different fermentation methods. Int. J. Eng. Technol. IJET-IJENS, 11(5), 90-98.

Park, J. K., Jung, J. Y., \& Park, Y. H. (2003). Cellulose production by Gluconacetobacter hansenii in a medium containing ethanol. Biotechnology letters, 25(24), 2055-2059.

Pokalwar, S. U., Mishra, M. K., \& Manwar, A. V. (2010). Production of Cellulose by Gluconacetobacter sp. Recent Research in Science and Technology, 2(7).

Prudnikova S.V., Volova T.G., \& Shishatskaya E.I. Shtamm bakterii Komagataeibacter xylinus - produtsent bakterialnoi tsellulozy (A strain of bacterium Komagataeibacter xylinus - a producer of bacterial cellulose). RF Patent for an invention No. 2568605. Priority of 11 December 2014. Registered in the RF State Register on 27 October 2015 (in Russian)

Prudnikova S.V., Volova T.G., Shishatskaya E.I. Shtamm bakterii Komagataeibacter xylinus - produtsent bakterialnoi tsellulozy (A strain of bacterium Komagataeibacter xylinus - a producer of bacterial cellulose). RF Patent for an invention No. 2568605. Priority of 11 December 2014. Registered in the RF State Register on 27 October 2015 (in Russian)

Ruka, D. R., Simon, G. P., \& Dean, K. M. (2012). Altering the growth conditions of Gluconacetobacter xylinus to maximize the yield of bacterial cellulose. Carbohydrate polymers, 89(2), 613-622.

Saska, S., Barud, H. S., Gaspar, A. M. M., Marchetto, R., Ribeiro, S. J. L., \& Messaddeq, Y. (2011). Bacterial cellulosehydroxyapatite nanocomposites for bone regeneration. International journal of biomaterials, 1-8. 
Saxena, I. M., \& Brown, R. M. (2005). Cellulose biosynthesis: current views and evolving concepts. Annals of botany, 96(1), 9-21.

Schramm, M. \& Hestrin, S. (1954). Factors affecting production of cellulose at the air/liquid interface of a culture of Acetobacter xylinum. Microbiology, 11(1), 123-129.

Schumann, D. A., Wippermann, J., Klemm, D. O., Kramer, F., Koth, D., Kosmehl, H., ... \& Salehi-Gelani, S. (2009). Artificial vascular implants from bacterial cellulose: preliminary results of small arterial substitutes. Cellulose, 16(5), 877-885.

Surma-Ślusarska, B., Presler, S., \& Danielewicz, D. (2008). Characteristics of bacterial cellulose obtained from Acetobacter xylinum culture for application in papermaking. Fibres \& Textiles in Eastern Europe, (4 (69)), 108111.

Tanaka, M., Murakami, S., Shinke, R., \& Aoki, K. (2000). Genetic characteristics of cellulose-forming acetic acid bacteria identified phenotypically as Gluconacetobacter xylinus. Bioscience, biotechnology, and biochemistry, 64(4), 757760.

Vazquez, A., Foresti, M. L., Cerrutti, P., \& Galvagno, M. (2013). Bacterial cellulose from simple and low cost production media by Gluconacetobacter xylinus. Journal of Polymers and the Environment, 21(2), 545-554.

Yamada, Y., Yukphan, P., Lan Vu, H. T., Muramatsu, Y., Ochaikul, D., Tanasupawat, S., Nakagawa, Y. (2012). Description of Komagataeibacter gen. nov., with proposals of new combinations (Acetobacteraceae). The Journal of general and applied microbiology, 58(5), 397-404.

Yamada, Y., Yukphan, P., Lan Vu, H. T., Muramatsu, Y., Ochaikul, D., Tanasupawat, S., \& Nakagawa, Y. (2012). Description of Komagataeibacter gen. nov., with proposals of new combinations (Acetobacteraceae). The Journal of general and applied microbiology, 58(5), 397-404.

Yamanaka, S., \& Sugiyama, J. (2000). Structural modification of bacterial cellulose. Cellulose, 7(3), $213-225$.

Yoon, S. H., Jin, H. J., Kook, M. C., \& Pyun, Y. R. (2006). Electrically conductive bacterial cellulose by incorporation of carbon nanotubes. Biomacromolecules, 7(4), 1280-1284.

Zhijiang, C., Guang, Y., \& Kim, J. (2011). Biocompatible nanocomposites prepared by impregnating bacterial cellulose nanofibrils into poly (3-hydroxybutyrate). Current Applied Physics, 11(2), 247-249. 